\title{
Underpotential Deposition of Copper on Gold in Alkaline and Acidic Media.
}

\author{
Rafael A. Vicente*, Matheus B. C. de Souza, Pablo S. Fernández
}

\begin{abstract}
We studied the underpotential deposition (UPD) of copper on polycrystalline gold in both alkaline and acidic media to determine the dependence of the copper coverage on the equilibrium potential of the system and also the thermodynamic conditions for the formation of a copper monolayer. The behavior of the underpotential deposition was studied through potentiostatic and potentiodynamic experiments. Results shows that the process is slower in alkaline media and occurs at higher potentials due to the very low activity of $\mathrm{Cu}(\mathrm{II})$ ions in this condition.
\end{abstract}

\section{Key words:}

Electrochemistry, UPD, Copper.

\section{Introduction}

The UPD consists in electrodepositing a metal on a different metallic substrate, forming one metallic monolayer. This phenomenon occurs due to the interactions metal-substrate, which are more favorable than the interactions metal-metal. Thus, the metal deposits on the substrate, at electrochemical potentials more positive than that for the deposition of the metal on a substrate of the same metal ${ }^{1}$.

Structures formed by UPD are of great interest for presenting different electronic properties from those observed in the original metal and substrate ${ }^{2}$. The present work seeks to study the deposition of $\mathrm{Cu}$ on $\mathrm{Au}$ in acidic and alkaline media, with the aim of understanding the dependence between the electrochemical potential and the Cu coverage.

\section{Results and Discussion}

The electrodeposition of $\mathrm{Cu}$ was analyzed by cyclic voltammetry. Image 1 shows the cyclic voltammogram (CV) obtained in $\mathrm{NaOH}$ and $\mathrm{H}_{2} \mathrm{SO}_{4}$ solutions with and without the presence of $\mathrm{Cu}^{+2}$.
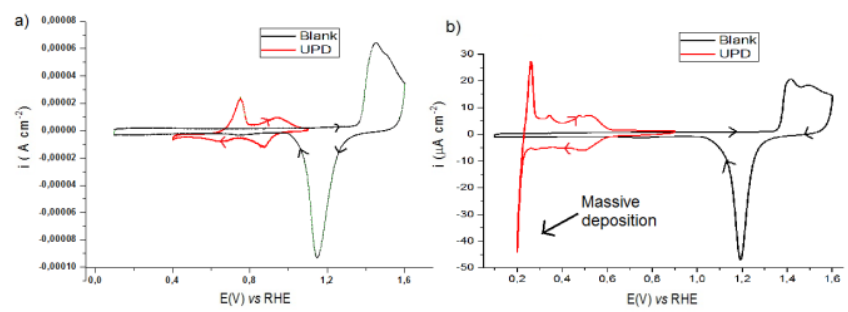

Image 1. (a) $\mathrm{CV}$ of $\mathrm{Au}$ in $0,5 \mathrm{~mol} \cdot \mathrm{L}^{-1} \mathrm{NaOH}$ (black) and 0,5 mol. $\mathrm{L}^{1} \mathrm{NaOH}+0,1 \mathrm{mmol}^{-1} \mathrm{CuSO}_{4}$ (red); (b) CV of $\mathrm{Au}$ in 0,5 mol.L-1 $\mathrm{H}_{2} \mathrm{SO}_{4}$ (black) and 0,5 mol. $\mathrm{L}^{-1} \mathrm{H}_{2} \mathrm{SO}_{4}+$ $0,1 \mathrm{mmol}^{-1} \mathrm{LuSO}_{4}$ (red). Scan rate: $10 \mathrm{mV} \cdot \mathrm{s}^{-1}$ and $1 \mathrm{mV} . \mathrm{s}^{-1}$, respectively.

The CVs in red were performed in regions were the UPD phenomena and the massive deposition $\left(\mathrm{Cu}^{+2}\right.$ on $\mathrm{Cu}$ ) occurs. The negative currents obtained during the negative sweep are due to the deposition of $\mathrm{Cu}^{+2}$ on $\mathrm{Au}$ and $\mathrm{Cu}$ and the positive currents are measured due to the dissolution of the atoms previously deposited. Image 1.(b) clearly illustrated the phenomena. In the negative sweep the deposition of $\mathrm{Cu}^{+2}$ on $\mathrm{Au}$ starts around $0,6 \mathrm{~V}$. The current continues being negative and without bigger variations until around $0,25 \mathrm{~V}$ when the massive deposition of $\mathrm{Cu}^{+2}$ on $\mathrm{Cu}$ occurs. The results in alkaline media are completely different (Image 1(a)). First of all, the UPD starts at around 0,95V, which is much closer to the $\mathrm{Au}$ oxide formation and reduction. Besides, there is not a clear feature in the CV, as it is in acidic media, showing the massive deposition of $\mathrm{Cu}^{+2}$.

The potential domain of the UPD can be determined by measuring the quantity of $\mathrm{Cu}$ deposited at different times at different potentials. Image 2.(b) shows similar desorption of $\mathrm{Cu}$ until $0,7 \mathrm{~V}$ for 1 and 5 minutes. For lower potentials the quantity deposited depends on the time, indicating a massive deposition. Image 2.(a) shows that around $0,7 \mathrm{~V}$ there is a sharp anodic peak, which is due to the desorption of the $\mathrm{Cu}$ massively deposited during the negative sweep.
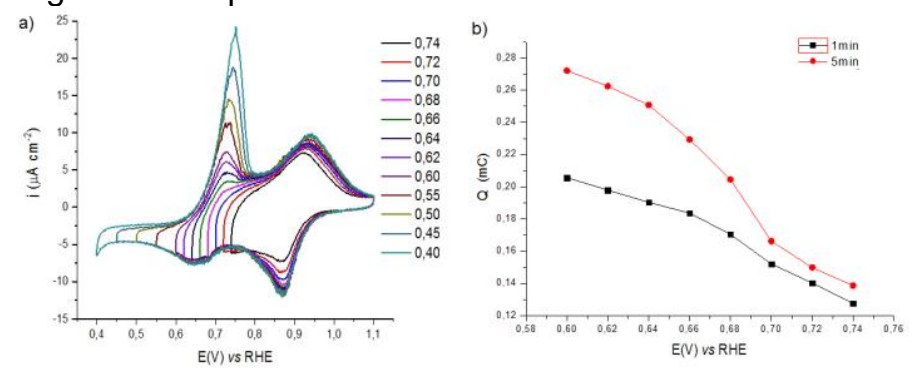

Image 2. (a) UPD in $0,5 \mathrm{~mol} . \mathrm{L}^{-1} \mathrm{NaOH}+0,1 \mathrm{mmol} \cdot \mathrm{L}^{-1}$ $\mathrm{CuSO}_{4}$ with variation of its inferior potential limit; Scan rate: $10 \mathrm{mV} . \mathrm{s}^{-1}$. (b) Variation of the charge obtained in the oxidation of $\mathrm{Cu}$ after polarization for different periods of time.

\section{Conclusions}

We determine for the first time the equilibrium potential domain of the UPD of $\mathrm{Cu}$ on Au in alkaline media. These findings permit to easily control the coverage of $\mathrm{Cu}$ atoms on Au. Using the results in both media we were able to calculate the activity of $\mathrm{Cu}^{+2}$ in our system. At this moment we are performing more experiments in order to obtain more precise results.

\section{Acknowledgement}

We thank FAPESP (Process number 2016/01365-0) and PRP-FAEPEX.

${ }^{1}$ Oviedo, O. A. et. al; Springer Intl. Publishing: Switzerland, 2016.

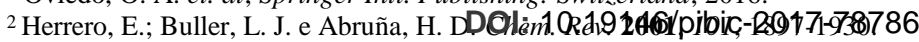
XXV Congresso de Iniciação Científica da UNICAMP 